\title{
Enhanced neural response to anticipation, effort and consummation of reward and aversion during Bupropion treatment
}

Article

Accepted Version

Dean, Z., Horndasch, S., Giannopoulos, P. and McCabe, C. (2016) Enhanced neural response to anticipation, effort and consummation of reward and aversion during Bupropion treatment. Psychological Medicine, 46 (11). pp. 2263-2274. ISSN 1469-8978 doi:

https://doi.org/10.1017/S003329171600088X Available at https://centaur.reading.ac.uk/62183/

It is advisable to refer to the publisher's version if you intend to cite from the work. See Guidance on citing.

To link to this article DOI: http://dx.doi.org/10.1017/S003329171600088X

Publisher: Cambridge University Press

All outputs in CentAUR are protected by Intellectual Property Rights law, including copyright law. Copyright and IPR is retained by the creators or other copyright holders. Terms and conditions for use of this material are defined in the End User Agreement. 


\section{CentAUR}

Central Archive at the University of Reading

Reading's research outputs online 
Title:

Enhanced Neural Response to Anticipation, Effort and Consummation of Reward and Aversion during Bupropion Treatment.

\section{Running Title:}

Effect of Bupropion on Neural Reward.

Zola Dean (MSc), Stefanie Horndasch (MD), Panagiotis Giannopoulos (MD MRCPsych) \& Ciara $\operatorname{McCabe}(\mathrm{PhD})^{*}$

School of Psychology and Clinical Language Sciences, University of Reading, UK.

* Corresponding author:

Dr Ciara McCabe

Lecturer in Neuroscience,

School of Psychology and Clinical Language Sciences,

University of Reading,

Reading RG6 6AL,

Tel: +44118378 5450

c.mccabe@reading.ac.uk

\section{Financial support}

This study was supported by the University of Reading start-up fund for Dr. C McCabe. 


\section{Abstract}

\section{Background}

We have previously shown that the selective serotonergic re-uptake inhibitor, citalopram, reduces the neural response to reward and aversion in healthy volunteers. We suggest that this inhibitory effect might underlie the emotional blunting reported by patients on these medications. Bupropion is a dopaminergic and noradrenergic re-uptake inhibitor and has been suggested to have more therapeutic effects on reward-related deficits. However, how bupropion affects the neural responses to reward and aversion is unclear.

\section{Methods}

17 healthy volunteers ( 9 female, 8 male) received 7 days of bupropion $(150 \mathrm{mg} /$ day $)$ and 7 days of placebo treatment, in a double-blind crossover design. Our functional Magnetic Resonance Imaging task consisted of 3 phases; an anticipatory phase (pleasant or unpleasant cue), an effort phase (button presses to achieve a pleasant taste or to avoid an unpleasant taste) and a consummatory phase (pleasant or unpleasant tastes). Volunteers also rated wanting, pleasantness and intensity of the tastes.

\section{Results}

Relative to placebo, bupropion increased activity during the anticipation phase in the ventral medial prefrontal cortex (vmPFC) and caudate. During the effort phase, bupropion increased activity in the vmPFC, striatum, dorsal anterior cingulate cortex and primary motor cortex. Bupropion also increased medial orbitofrontal cortex, amygdala and ventral striatum activity during the consummatory phase.

\section{Conclusions}

Our results are the first to show that bupropion can increase neural responses during the anticipation, effort and consummation of rewarding and aversive stimuli. This supports the notion that bupropion might be beneficial for depressed patients with reward-related deficits and blunted affect. 


\section{Introduction}

Defined as the inability to experience pleasure from normally rewarding stimuli, anhedonia is one of the two main diagnostic criteria for depression. Studies examining the effects of the current antidepressant treatments, selective serotonin reuptake inhibitors (SSRI), have found that the symptom of anhedonia is not effectively treated, which in turn predicts a longer time to recovery and fewer depression-free days (Shelton and Tomarken, 2001, Spijker et al., 2001). Further, there are reports that SSRIs can in fact contribute to emotional blunting in patients, where experiences, both positive and negative, are flattened (Price et al., 2009). It has therefore been suggested that different pharmacological targets might be needed to adequately treat anhedonia and apathy in depression (Dunlop and Nemeroff, 2007, McCabe et al., 2009a, Nutt et al., 2007)

Anhedonia is multi-dimensional, with the anticipatory (appetitive/wanting) and consummatory (hedonic/liking) dimensions being the most widely examined in depression (Frey et al., 2015, McCabe, 2014, Nutt et al., 2007). Affective neuroscience studies of reward 'wanting' and 'liking' have suggested that these psychological processes map onto distinct brain reward systems. For example, studies of pleasure identify hedonic impact in the ventral pallidum, nucleus accumbens and orbitofrontal cortex (OFC) (Berridge and Kringelbach, 2008, Peciña, 2008, Peciña and Berridge, 2005, Peciña et al., 2006, Smith and Berridge, 2005, Wheeler and Carelli, 2006), whereas "wanting" or incentive salience is mediated by neural systems that include mesolimbic dopamine projections from the ventral tegmental area to the ventral striatum (Berridge, 2007, Berridge et al., 2009). Further, dopamine has been shown to be involved in the learning about rewards in prefrontal cortical regions, such as the anterior cingulate cortex and the OFC (Dayan and Balleine, 2002).

Examining the neural correlates of anhedonia in depression, studies have found reduced anticipatory and consummatory responses to reward in the ventral and dorsal striatum and the anterior cingulate (Epstein et al., 2006, Forbes et al., 2009, Pizzagalli et al., 2009a, Smoski et al., 2009, Ubl et al., 2015, Zhang et al., 2013), with increased activity to the anticipation of gains in the anterior cingulate (Knutson et al., 2008). Unfortunately few studies investigate the separate dimensions of anhedonia within the same task, which may account for overlapping regions activated across studies in depression (Treadway and Zald, 2011, Zhang et al., 2013). Recent behavioural evidence suggests impairments in the amount of effort expended for rewards 
in depressed patients (Sherdell et al., 2012, Treadway et al., 2012, Yang et al., 2014), suggesting another possible conceptual dimension of anhedonia needing further investigation. How effort expenditure might map onto neural processes in depression is as yet unclear.

Studies examining the neural response to aversive stimuli in depression are less consistent, with some finding increased responses in regions such as the amygdala (Knutson and Greer, 2008, Sheline et al., 2001, Surguladze et al., 2004), whilst others find reduced/blunted responses in the amygdala and lateral OFC (Bylsma et al., 2008, Luking et al., 2015, McCabe et al., 2009a). However, blunted responses to both reward and aversion fits with the theory of Emotion Context Insensitivity in depression, whereby patients exhibit reduced reactivity to all emotional stimuli (Rottenberg, 2007, Rottenberg et al., 2005).

To assess the neural response to both reward and aversion, we have developed an experimental model that utilizes pleasant and unpleasant sights and tastes. We have previously shown that the SSRI, citalopram, reduced the neural response to the anticipation of reward in the ventral striatum, medial OFC and ventral medial prefrontal cortex (vmPFC) and in the ventral striatum to the taste of the reward (consummatory) (McCabe et al., 2010). Citalopram also reduced the neural activation to the anticipation of aversion in the insula and lateral OFC and to the aversive taste in the insula (consummatory) (McCabe et al., 2010). We suggested that this general inhibitory effect might underlie the emotional dampening associated with SSRIs and their alleged inability to effectively treat reward-related deficits in depression (Kumar et al., 2008, Opbroek et al., 2002, Price et al., 2009, Shelton and Tomarken, 2001).

It has been suggested, however, that catecholamine antidepressants like bupropion (dopamine and noradrenaline reuptake inhibitor, DNRI) (Dwoskin et al., 2006, Stahl et al., 2004) might be more efficacious at improving reward-related deficits and apathy in depression and less likely to cause the negative sideeffects of sexual dysfunction seen with SSRIs (Argyropoulos and Nutt, 2013, M Pereira et al., 2014, Nutt et al., 2007, Shelton and Tomarken, 2001). In fact a recent study examining the human response to erotic images found increased activity in the posterior midcingulate cortex, mediodorsal thalamus, and extended amygdala under bupropion (Abler et al., 2011). However, how the separate dimensions of neural reward and aversion processing (anticipation, effort and consummation) might be affected by bupropion is unknown and is therefore the aim of the current study. To do this we included in our task an anticipatory phase (pleasant or unpleasant cue), an effort phase (button presses to achieve a pleasant taste or to avoid an unpleasant taste) and a consummatory phase (pleasant or unpleasant tastes). We hypothesized that, unlike our previous results 
with citalopram, bupropion would increase neural responses during anticipation in areas such as the striatum and anterior cingulate cortex. Further, we expected that during the effort phase bupropion would increase the neural activation in regions such as the striatum and prefrontal cortex, as these regions have recently been shown to be activated when working for rewards and avoiding aversion (Delgado et al., 2009, Wiers et al., 2014). Additionally, we hypothesized that bupropion would increase neural responses in the striatum and medial OFC during the consummatory phase, given their involvement in hedonic processing. Finally, as with our previous work on the effects of 7 day treatments with antidepressants in healthy volunteers, we expected to find no observable behavioural effects on effort or subjective ratings for each of the stimuli (Harmer et al., 2009, McCabe et al., 2010). 


\section{Materials and Methods}

\section{Participants}

17 healthy right-handed and Caucasian volunteers (mean 24 years, nine female), were randomized to receive 7 days oral treatment with bupropion $(150 \mathrm{mg} /$ day $)$ and 7 days oral treatment with placebo separated by a 2 -week washout phase in a double-blind between-groups design. Our previous fMRI study indicated an effect size of $d=0.4$ with a mean standard deviation of 0.25 (McCabe et al., 2009b), demonstrating that a sample size of 15 would be required to achieve $80 \%$ power at an alpha level of $5 \%$. The study was located at the Centre for Neuroscience and Neurodynamics (CINN) in the Department of Psychology at the University of Reading. Volunteers were recruited via advertisement and, after reading study information, provided written consent prior to screening. Ethical approval was obtained from the University of Reading.

The exclusion criteria included current/previous psychiatric disorder (including alcohol or drug dependency) using the DSM-IV Structured Clinical Interview [SCID (Spitzer et al., 2004)], pregnancy and any contraindications to MRI and bupropion (including family history of bipolar disorder and seizures/epilepsy). Volunteers were medication-free for the past 3 months (excluding the contraceptive pill) before starting the study and underwent a physical examination. Volunteers had a healthy BMI and their liking and craving for chocolate was measured using a questionnaire (Rolls and McCabe, 2007). Eleven volunteers were non-smokers, four smoked $<1$ cigarette a week, one smoked 5 cigarettes per week and one smoked 1-2 cigarettes a day on average. Baseline measures of mood and anhedonia were taken using the Beck Depression Inventory (Beck et al., 1961), Snaith-Hamilton Pleasure Scale (Snaith et al., 1995), Fawcett-Clarke Pleasure Capacity Scale (Fawcett et al., 1983), Temporal Experience of Positive Mood (Gard et al., 2007) and Behavioral Inhibition/Activation Scales (Carver and White, 1994). Given that we use taste stimuli, including chocolate, volunteers also completed the Eating Attitudes Questionnaire (Garner et al., 1982) to assess eating attitudes.

\section{Experimental design}

The study used a double blind, within-subjects, counterbalanced, crossover design. Volunteers received 7 days ( 1 tablet each morning) of bupropion treatment (150mg/day) and 7 days of placebo treatment, 
separated by a 2-week washout phase. Treatment order was randomised, with 9 volunteers receiving bupropion first and 8 receiving placebo first. Volunteers underwent an fMRI scan on the 7th day of each treatment at approx. $3 \mathrm{hrs}$ after last dose. One volunteer had a scan after 6 days treatment (drug) due to experiencing adverse side-effects. Medication was provided by the Oxford Health NHS Foundation Trust and the Royal Free London NHS Foundation Trust. Participants were asked to not consume chocolate for 24 hours prior to scanning and were allowed only one caffeinated drink on the scan morning. Before scans, volunteers completed the Patient Rated Inventory of Side Effects (PRISE: Sequenced Treatment Alternatives to Relieve Depression) to record any adverse side-effects. Mood was measured before and after scans using the befindlichkeit scale of mood and energy (von Zerssen et al., 1974) and a mood visual analogue scale (VAS).

The task was adapted from (McCabe et al., 2010) to include an effort phase (Figure S1). The task (40 trials) had 4 conditions based on the trial type (reward/aversive) and its level of difficulty (easy/hard).

Trial type was cued by a visual stimulus (chocolate picture or a picture of a mouldy drink, $2 \mathrm{sec}$, anticipatory phase), which indicated either to work to win the chocolate taste or to avoid the unpleasant taste. Difficulty was determined by the amount of effort required to complete the effort phase (easy $=24$, hard $=45$ button presses). The effort phase, required volunteers to press a button as fast as possible $(<6 \mathrm{sec})$ to move a bar towards the pleasant chocolate picture (reward) and away from the unpleasant mouldy picture (aversive), allowing enough time to complete easy trials but not hard. A taste was then delivered (consummatory phase) based on performance. If on reward trials volunteers were successful they received the taste ( 5 sec delivery and $2 \mathrm{sec}$ swallow cue) of chocolate and if not they received the tasteless solution. If on aversive trials volunteers were successful they received the tasteless solution and if not they received the unpleasant taste. A grey image $(2 \mathrm{sec})$ followed by a tasteless rinse was presented at the end of each trial. Each condition was repeated 10 times, chosen by random permutation. Jitters were used for both interstimulus intervals and inter-trial intervals. To sustain effort, 4 trials ( 2 reward/2 aversive) were longer at 9 sec each. Volunteers also rated 'wanting', 'pleasantness' ( +2 to -2$)$ and 'intensity' $(0$ to +4$)$ on a VAS on each trial (Figure $S 1)$.

\section{Stimuli}

We used a picture of liquid chocolate (reward), a mouldy drink (aversive) and a grey image (control). The rewarding taste was a Belgian chocolate drink and the aversive taste was a combination of the 
chocolate drink mixed with beetroot juice, providing a similar texture. The tasteless solution $\left(25 \times 10^{-3} \mathrm{~mol} / \mathrm{L}\right.$ $\mathrm{KCL}$ and $2.5 \times 10^{-3} \mathrm{~mol} / \mathrm{L} \mathrm{NaHCO}_{3}$ in distilled $\mathrm{H}_{2} \mathrm{O}$ ) was also used as a rinse between trials. This was subtracted from the effects of the other taste stimuli to allow somatosensory and mouth movement effects to be removed (de Araujo et al., 2003, O'Doherty et al., 2001). Solutions were delivered through three teflon tubes held together by a plastic mouthpiece and connected by a one-way syringe-activated check valve (Model 14044-5, World Precision Instruments, Inc.), allowing $0.5 \mathrm{~mL}$ of solution to be manually delivered.

\section{fMRI Scan}

The experimental protocol consisted of an event-related interleaved design. A Siemens Magnetom Trio 3T whole body MRI scanner and a thirty-two-channel head coil were used. Multi-band accelerated pulse sequencing (Version number RO12 Center for Magnetic Resonance Research, University of Minnesota, EPI 2D BOLD/SE/DIFF Sequence) was used with an acceleration factor of 6. T2*-weighted echo planner imaging slices were obtained every 0.7 seconds (TR). Imaging parameters were chosen to reduce distortion artefact in the orbitofrontal cortex (Wilson et al., 2002). 54 Axial slices with in-plane resolution of $2.4 \times 2.4 \mathrm{~mm}$ and between plane spacing of $2.4 \mathrm{~mm}$ were attained. The matrix size was $96 \times 96$ and the field of view were $230 \times 230 \mathrm{~mm}$. Acquisition was performed during task performance, yielding approximately 3500 volumes. An anatomical T1 volume with sagittal plane slice thickness $1 \mathrm{~mm}$ and in-plane resolution of $1.0 \times 1.0 \mathrm{~mm}$ was also acquired.

\section{fMRI analysis}

Statistical Parametric Mapping (SPM8: http://www.fil.ion.ucl.ac.uk/spm/software/spm8/) was used to analyze the imaging data. The data was pre-processed using realignment, normalization to the Montreal Neurological Institute (MNI) coordinate system and spatial smoothing with a 6-mm full-width-at-halfmaximum Gaussian kernel and global scaling (Collins et al., 1994). The time series at each voxel was lowpass filtered with a hemodynamic response kernel. Time series non-sphericity at each voxel was estimated and corrected for (Friston et al., 2002), and a high-pass filter with a cut-off period of $128 \mathrm{sec}$ was applied.

In the single-event design, a general linear model was then applied to the time course of activation in which stimulus onsets were modelled as single impulse response functions and then convolved with the 
canonical hemodynamic response function (Friston et al., 1994). Linear contrasts were defined to test specific effects. Time derivatives were included in the basis functions set. Following smoothness estimation (Worsley et al., 1996), linear contrasts of parameter estimates were defined to test the specific effects of each condition (pleasant/unpleasant cue - grey image and pleasant/unpleasant taste - rinse) with each individual dataset. Voxel values for each contrast resulted in a statistical parametric map of the corresponding $t$ statistic, which was then transformed into the unit normal distribution (SPM $z$ ). Movement parameters for each person were added as additional regressors in the $1^{\text {st }}$ level analyses.

Second-level fMRI analyses first examined simple main effects of task with one-sample $t$-tests for all scans (Table S1). These results were thresholded at $p=0.05$ uncorrected and whole-brain cluster corrected [p $<0.05$ family-wise error (FWE) for multiple comparisons]. To examine the effect of bupropion, the oneway ANOVA within-participants design implemented in SPM8 was used and all data were reported thresholded at $p=0.05$ uncorrected and whole-brain cluster corrected $(p<0.05 \mathrm{FWE}$ for multiple comparisons). Regions of interest, for which we had a priori hypotheses based our previous studies using a similar paradigm in healthy controls, were; ventral striatum [10, 12, -6; -6, 12, -4] (McCabe et al., 2010), caudate $[-10,12,0 ;-10,14,0]$ (McCabe et al., 2010), medial OFC [2, 32, -24] (McCabe et al., 2010), vmPFC $[8,56,-12 ; 2,44,-14]$ (McCabe et al., 2009b, McCabe et al., 2010) and lateral OFC [46, 34, -6] (McCabe et al., 2010). Peaks within $15 \mathrm{~mm}$ of these locations and with a cluster threshold of at least 30 contiguous voxels had small volume corrections for multiple comparisons applied (FWE, $p<0.05$ ). Plots of contrast estimates were extracted with plots tool in SPM8, and WFU Pick Atlas (http://www.fmri.wfubmc.edu/cms/software) was used to display neural activation, with error bars representing the standard error of the mean. Activation co-ordinates are listed in the stereotactic space of the MNI ICBM 152 brain (Table 2).

\section{Behavioral Data}

Data was analyzed using repeated measures ANOVA and employed the Bonferroni correction for multiple comparisons. Where sphericity was violated, the Greenhouse-Geisser correction was utilized. Notnormally distributed data was transformed and reanalyzed. The reanalyzed data did not differ from raw data analysis and thus results are reported using the original data. Caution, however, might be paid to interpretation of the VAS analysis, because a proportion of the data was not normally distributed. 


\section{Results}

\section{Demographic Details and Mood Ratings}

Demographic data (Table 1) indicated that participants had low depression and anhedonia scores, as measured on range of mood and anhedonia questionnaires. Volunteers also scored low on the EAT and reported a strong liking of chocolate. A repeated-measures ANOVA was performed to examine the effect of treatment (bupropion/placebo) and time (pre/post scan) on mood and affect, as measured by the BFS and VAS (Table S2). Results revealed that there was no significant effect of treatment $[\mathrm{F}(1,16)=.483, p=.497]$, time $[F(1,16)=.822, p=.378]$, treatment by time $[F(1,16)=1.922, p=.185]$, treatment by VAS $[F(1,16)=2.472$, $p=.084]$ or treatment by time by VAS interactions $[F(1,16)=.689, p=.545]$. There was also no significant effect of treatment $[F(1,14)=1.61, p=.225]$ or treatment by time interaction $[F(1,14)=2.176, p=.162]$ on total BFS scores. However, there was a significant main effect of time on overall BFS score $[F(1,14)=5.879$, $p=.029]$. 


\section{Adverse effects}

Table S3 reports the number of adverse effects experienced on each treatment, as measured on the PRISE. The most commonly reported adverse effects across both treatment phases were headache $(\mathrm{N}=5$ per treatment), difficulty sleeping ( $\mathrm{N}=3$ per treatment) and fatigue ( $\mathrm{N}=3$ placebo, $\mathrm{N}=5$ bupropion). Dizziness $(\mathrm{N}=4)$ was the most commonly reported adverse effect in the bupropion condition that was not reported in the placebo condition.

\section{Subjective Ratings of Stimuli}

Volunteers rated the chocolate cue and taste as pleasant and the unpleasant picture and taste as unpleasant (Figure S3). Using repeated-measures ANOVA with Ratings as the first factor with three levels (wanting, pleasantness and intensity), Treatment as the second factor with two levels (bupropion and placebo) and Condition as the third factor with two levels (rewarding and aversive), there was no significant main effect of treatment $[F(1,16)=.867, p=.366]$ or treatment by condition interaction $[F(1,16)=2.558$, $p=.129]$, treatment by rating interaction $[F(1,16)=.109, p=.802]$ or treatment by rating by condition interaction $[F(1,16)=.701, p=.479]$.

\section{Behavioral responses}

To examine whether there was an effect of treatment on the amount of effort invested into each condition (reward/aversion), repeated-measures ANOVAs were conducted on the average number of button presses made and the average amount of time it took to complete the effort stage (Figure S4). With Treatment (bupropion and placebo) and Condition (reward and aversion) included as factors, it was revealed that volunteers made significantly more button presses on aversive trials $(M=37.69, S E=0.33)$ compared to reward trials $(M=37.37, S E=0.34)[F(1,16)=5.736, p=0.029]$. This was independent of treatment, since there was no main effect of treatment $[F(1,16)=.028, p=.869]$ or treatment by condition interaction $[F(1,16)=.063$, $p=.804]$. Furthermore, although volunteers completed aversive trials $(M=5519.33 \mathrm{~ms}, S E=46.43)$ quicker than reward trials $(M=5546.57 \mathrm{~ms}, S E=45.11)$, this was not significant $[F(1,16)=2.106, p=.166]$, nor was there a main effect of treatment $[F(1,16)=.023, p=.881]$ or treatment by condition interaction $[F(1,16)=1.654$, $\mathrm{p}=.217]$. 
Table S1 in the Supplementary Material provides a summary of the results for each contrast across all volunteers to indicate the main effect of task. Table 2 provides a summary of the results of the interaction with Treatment.

Table 2. Regions showing significant effect of treatment on each condition.

\section{MNI coordinates}

\begin{tabular}{lllllll}
\hline Brain Region & X & Y & Z & Z score & Significance \\
& & & & & $(p$ Value $)$
\end{tabular}

\section{Anticipatory}

Chocolate cue: bupropion > placebo

$\begin{array}{lccccc}\text { lOFC } & -42 & 44 & -12 & 4.11 & 0.001^{*} \\ \text { Caudate } & -6 & 16 & 6 & 3.73 & 0.007^{*} \\ & & & & & \\ \text { pgACC/vmPFC } & 8 & 40 & -8 & 3.33 & 0.02^{*}\end{array}$

Unpleasant cue: bupropion > placebo

$\begin{array}{llllll}\text { vmPFC } & -12 & 48 & 0 & 3.98 & 0.003^{*}\end{array}$

$\begin{array}{lllllll}\text { Caudate } & -4 & 16 & 6 & 3.61 & 0.01^{*}\end{array}$

Easy chocolate - hard chocolate:

bupropion > placebo

$\begin{array}{llllll}\text { vmPFC } & 12 & 50 & 0 & 4.09 & <0.001 \\ \text { Caudate } & 10 & 6 & 2 & 3.97 & <0.001\end{array}$


Putamen

$\mathrm{dACC} /$ paracingulate gyrus
$-14 \quad 8-0$

$-6 \quad 28$

42

3.45

$<0.001$

Easy unpleasant - hard unpleasant:

bupropion > placebo

Ventral striatum/caudate

Primary motor cortex
$-1$

20

$-6$

3.42

$<0.001$

$-38$

50

4.06

$<0.001$

Easy chocolate - easy unpleasant:

bupropion > placebo

Superior frontal gyrus

$-2$

46

4.30

$<0.001$

$\mathrm{dACC} /$ paracingulate gyrus

$6 \quad 28$

42

4.10

$<0.001$

\section{Consummatory}

Chocolate taste: bupropion > placebo
mOFC
$\begin{array}{lll}-2 & 28 & -20\end{array}$
3.67
$0.005^{*}$

Chocolate taste: placebo > bupropion

Caudate

$-2$

8

10

4.07

$<0.001$

\section{Unpleasant taste: bupropion > placebo}

$\begin{array}{lccccc}\text { mOFC } & -2 & 28 & -20 & 3.76 & 0.014 \\ \text { Amygdala } & 28 & -2 & -26 & 3.26 & 0.014 \\ & 12 & 6 & -6 & 3.11 & 0.014\end{array}$

Data thresholded at $\mathrm{p}=0.05$ uncorrected.

$p$ values, Family Wise Error Whole brain fully corrected or *Family Wise Error small volume correction $p<0.05$.

pgACC, pregenual anterior cingulate cortex; vmPFC, ventromedial prefrontal cortex; dACC, dorsal anterior cingulate; mOFC, medial orbitofrontal cortex; Mid OFC, middle orbitofrontal cortex; 1OFC, lateral 
orbitofrontal cortex; Cing, cingulate

\section{Main Effect of Task}

As expected, the chocolate stimuli activated reward-related areas, such as the ventral striatum, the anterior cingulate and the OFC, whereas the unpleasant stimuli activated regions including the amygdala and 1OFC. Both the chocolate taste and unpleasant tastes activated the insula (i.e. the primary taste cortex).

\section{Anticipatory Phase}

Relative to the placebo condition, the bupropion condition showed increased BOLD activity in the caudate in response to both the pleasant and unpleasant cue. To the pleasant cue, the bupropion condition showed more activity in the pgACC/vmPFC (Fig 1) and 1OFC, in comparison to placebo. To the unpleasant cue, the bupropion condition showed more BOLD activity in the vmPFC, relative to placebo.
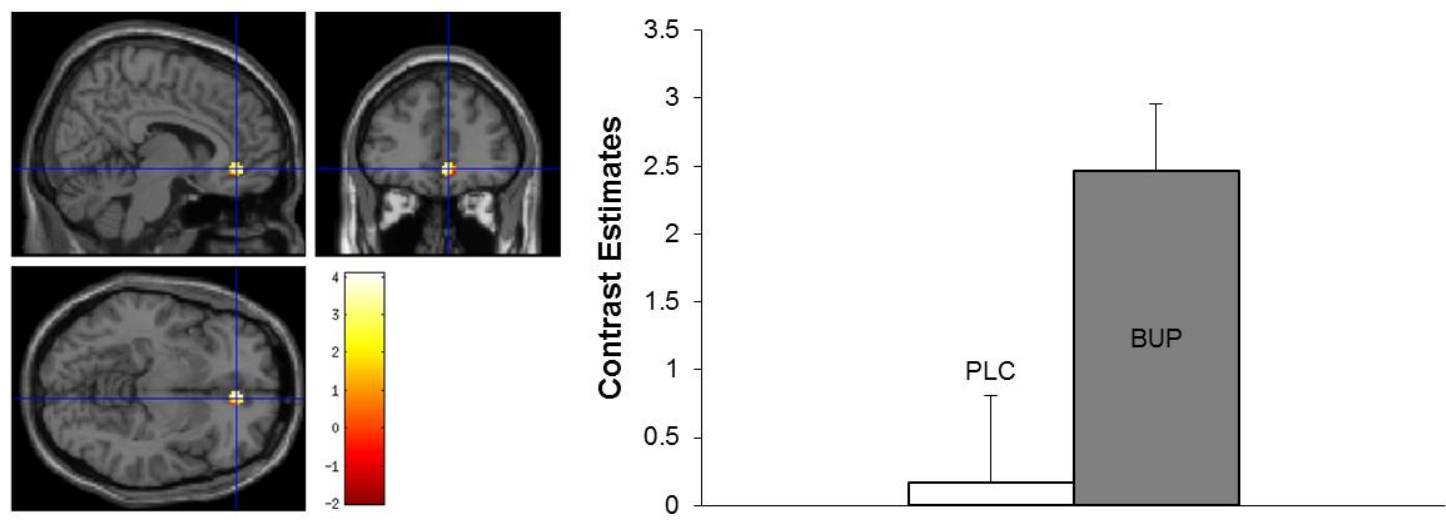

Figure 1. Pleasant cue: left panel, axial, sagittal and coronal image of pgACC/vmPFC activation compared to placebo $(Z=3.33, p=0.02 \mathrm{FWE}$ svc for multiple comparisons); right panel, contrast estimates for paACC centered at 8, 40, -8. Error bars represent the standard error of the mean.

\section{Effort Phase}

For bupropion there was increased BOLD activity in the caudate, vmPFC (Figure 2), dACC/paracingulate gyrus and putamen for the easy chocolate trials compared to hard chocolate trials, in comparison to placebo. Bupropion also increased BOLD activity in the primary motor cortex and ventral 
striatum/caudate for the easy unpleasant trials compared to hard unpleasant trials. Bupropion increased BOLD activity in the dorsal anterior cingulate cortex (dACC)/paracingulate gyrus and the superior frontal gyrus for the easy chocolate trials compared to the easy aversive trials, relative to placebo.
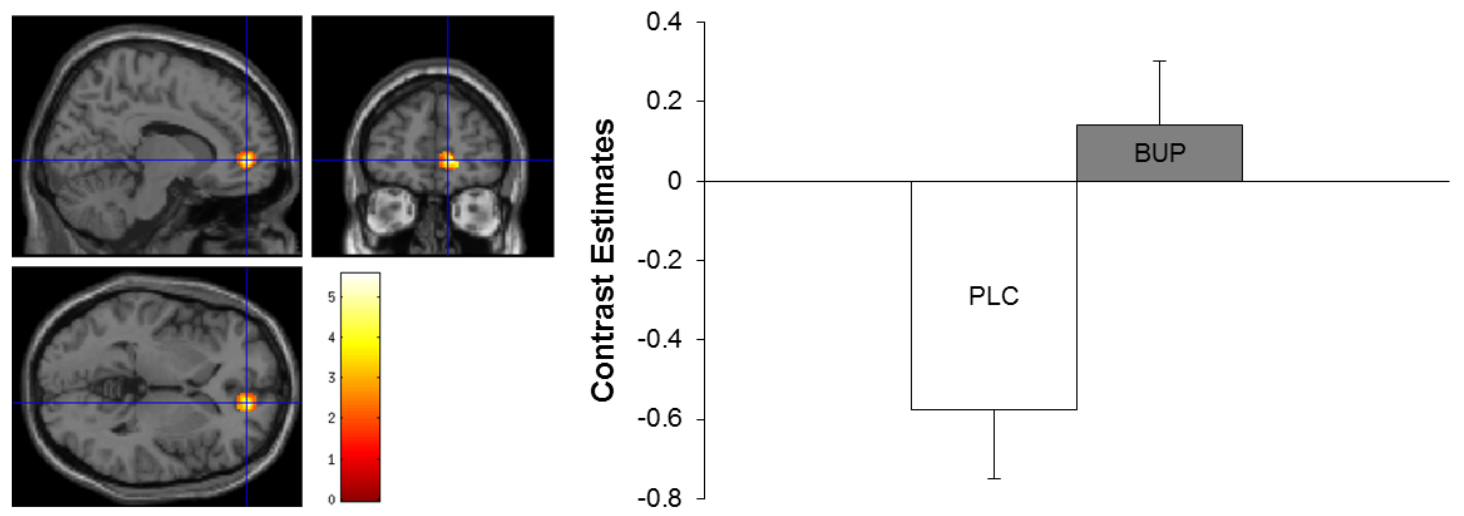

Figure 2. Easy effort chocolate - hard effort chocolate: left panel, axial, sagittal and coronal image of vmPFC activation compared to placebo $(Z=4.09, p<0.001 \mathrm{FWE}$ whole brain cluster corrected for multiple comparisons); right panel, contrast estimates for vmPFC centered at 12, 50, 0. Error bars represent the standard error of the mean.

\section{Consummatory Phase}

Bupropion increased BOLD activity in the mOFC to both the pleasant (Figure 3) and unpleasant tastes. Bupropion increased BOLD activity in the amygdala (Figure 4) and ventral striatum for the unpleasant taste relative to the placebo condition. Bupropion also reduced BOLD activity for the pleasant taste in the caudate, relative to the placebo condition. 

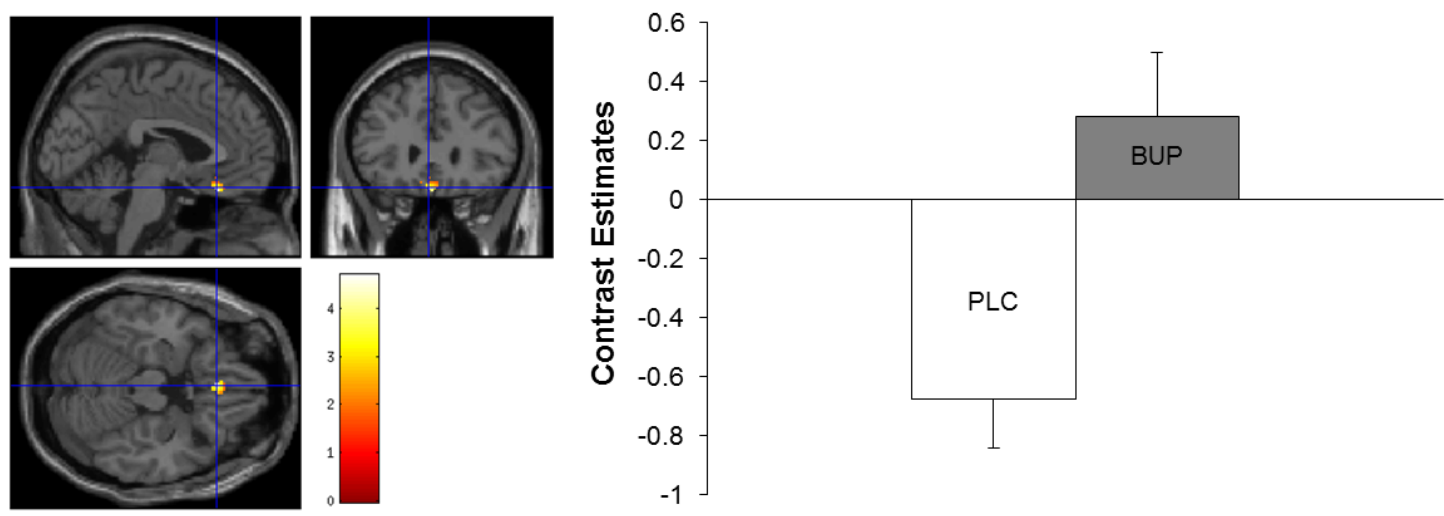

Figure 3. Chocolate taste: left panel, axial, sagittal and coronal image of mOFC activation compared to placebo $(Z=3.67, p=0.005 \mathrm{FWE}$ svc for multiple comparisons); right panel, contrast estimates for mOFC centered at 45, -2, 28. Error bars represent the standard error of the mean.
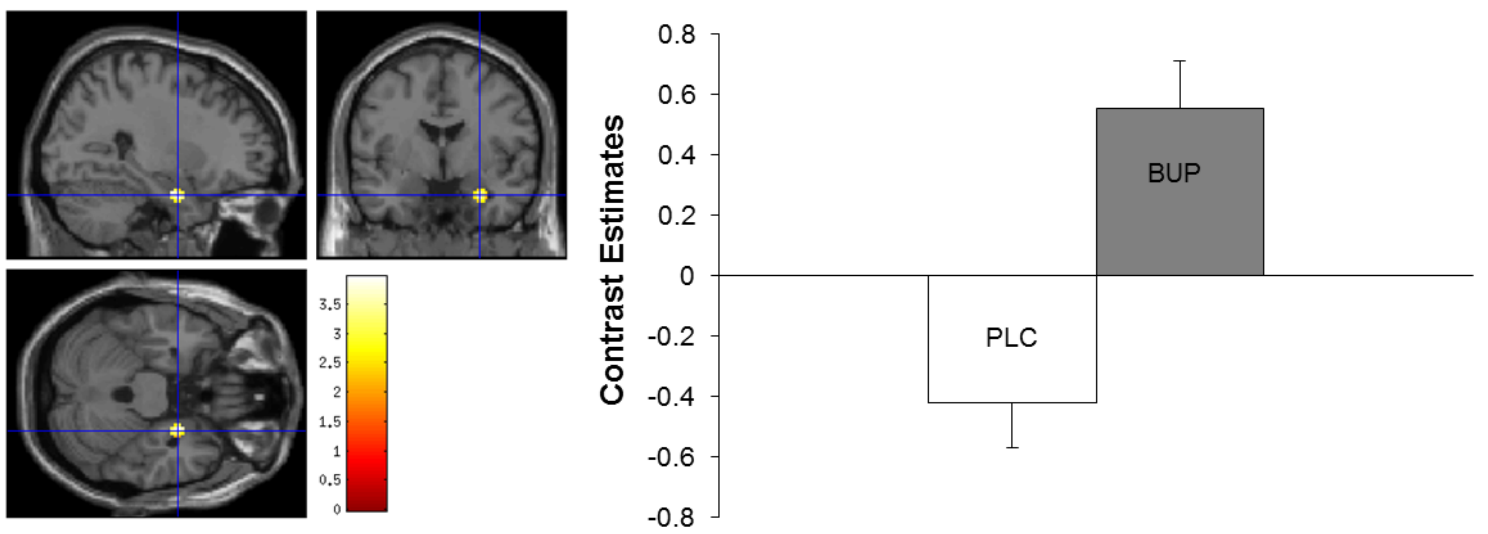

Figure 4. Unpleasant taste: left panel, axial, sagittal and coronal image of amygdala activation compared to placebo ( $Z=3.26, p=0.014 \mathrm{FWE}$ whole brain cluster corrected for multiple comparisons); right panel, contrast estimates for amygdala centered at 28,-2,-26. Error bars represent the standard error of the mean. 


\section{Discussion}

The aim of this study was to examine the effects of 7 days treatment with bupropion on the neural response to three phases of reward and aversion processing (anticipation, effort and consummation) in healthy volunteers. We found that bupropion increased neural responses during the anticipation, effort to achieve/avoid and the consummation of rewarding and aversive tastes. The effects on reward are consistent with the proposal that bupropion may significantly improve outcomes for depressed patients with predominant symptoms of decreased pleasure, interest and energy (Corcoran et al., 2004, Nutt et al., 2007). Further, bupropions ability to increase neural responses during anticipation, avoidance and consummation of aversive stimuli may be additionally beneficial for patients experiencing blunted affect in depression whereby reduced reactivity to positive and negative stimuli is predominant (Rottenberg, 2007, Rottenberg et al., 2005).

Specifically we found that bupropion increased activity during the anticipation phase (pleasant and unpleasant cues) in the vmPFC and the caudate, with increased lateral OFC to the pleasant cue. These regions are recruited during anticipation of reward (Kim et al., 2010, Sescousse et al., 2013) and found blunted to the anticipation of reward in patients with depression (McCabe et al., 2009a, Price and Drevets, 2009). We also found that the caudate was increased during the anticipation phase (pleasant and unpleasant cues) in the bupropion group compared to placebo. The caudate, which has been previously shown to be activated during the anticipation of pleasant and unpleasant stimuli in healthy volunteers (Knutson et al., 2001; Greenberg et al., 2015) has been found hypoactive during the anticipation of reward in people with depression (Forbes et al., 2009, Smoski et al., 2009, Zhang et al., 2013). Thus bupropions ability to modulate activation in these regions during anticipation of reward and aversion might be a mechanism by which catecholaminergic medications are less likely to cause emotional blunting in depression compared to SSRI medications (Argyropoulos and Nutt, 2013, Bylsma et al., 2008, Nutt et al., 2007, Shelton and Tomarken, 2001).

During the effort phase, we found that there was more neural activity under hard trials than easy in the placebo group (Figure S2). We found that the activity under easy trials was potentiated by bupropion, in the striatum, vmPFC (Figure 2) and the dACC/motor areas, relative to placebo. Given the previous work showing that these regions are implicated in various processes involved in reward processing including 
motor performance (Liljeholm and O’Doherty, 2012, Scholl et al., 2015) and in the avoidance of aversion (Kerr et al., 2012), its perhaps not surprising that bupropion enhanced this neural activity during effort expenditure to achieve reward and avoid aversion.

During the consummatory phase we found that bupropion, compared to placebo, increased neural activity for both pleasant and unpleasant tastes in the mOFC. Our results are consistent with the literature indicating the involvement of the mOFC in hedonic experiences in humans and animals (Kringelbach, 2010, Peters and Buchel, 2010, Scott et al., 2005). Further, our previous study in those recovered from depression found reduced activity to the taste of chocolate (possible trait marker) in a similar subgenual/mOFC region to that enhanced by bupropion in this current study (McCabe et al., 2009a). Of note, a study by Pizaggalli et al. (2008) found reduced activations in depressed patients to both positive and negative outcomes in the striatum (Pizzagalli et al., 2009b) which is of interest given that we find enhanced striatal activation to the unpleasant taste under bupropion in our task. Taken together our results suggest that bupropion may be beneficial at increasing the neural deficits to both positive and negative consummatory stimuli in depressed patients who report blunted affect.

As expected, there was no significant treatment effect on the amount of effort invested in the task or on the subjective reports of pleasantness, wanting and intensity for each of the stimuli. This is similar to our previous studies with acute pharmacological challenges in healthy volunteers and suggests that enhanced neural processing of reward/aversion after 7 days treatment does not necessarily become the subject of conscious awareness, although it could still presumably influence behavior (Horder et al., McCabe et al., 2010, Tudge et al., 2015). Perhaps there is also a ceiling effect as volunteers are all healthy and do not have deficits in their ability to complete the effort component or to experience the tastes. However, how bupropion might affect these processes in studies with larger sample sizes and in depressed patients remains to be elucidated.

To conclude, we suggest a potential mechanism of beneficial antidepressant drug action of bupropion that consists of enhancing the neural activation to reward and aversion during anticipation, effort and consummation. This profile of activity in turn could promote reward-seeking and aversive-avoidant behaviors in patients with depression, whereby a lack of drive to actively seek and experience rewards is coupled with a lack of drive to actively avoid negative experiences. Our results also support the notion that non-serotonergic antidepressants may play an important role specifically for patients that have a blunted 
emotional affect and this fits with the Emotion Context Insensitivity theory of depression (Rottenberg et al., 2005). Future research on the effects of bupropion on anticipation, effort and consummation of reward and aversion processing in depressed patients are encouraged to explore this notion further.

\section{Financial support}

This study was supported by the University of Reading start-up fund for Dr. C McCabe.

\section{Conflict of interest}

Dr. McCabe has acted as a consultant to P1Vital, Givaudan, GWpharma, the British Broadcasting Company (BBC) and Channel 4. Zola Dean, Dr. Stefanie Horndasch and Dr. Panagiotis Giannopoulos report no biomedical financial interests or potential conflicts of interest.

\section{Ethical standards}

The authors assert that all procedures contributing to this work comply with the ethical standards of the relevant national and institutional committees on human experimentation and with the Helsinki Declaration of 1975, as revised in 2008.

\section{Acknowledgments}

We thank Dr. Mark Parry, MRCPsych consultant psychiatrist and college tutor at Prospect Park Hospital, NHS Berkshire Trust, Reading, UK for his clinical collaboration.

Supplementary information is available at the Psychological medicine website 
References

Abler, B., Seeringer, A., Hartmann, A., Gron, G., Metzger, C., Walter, M. \& Stingl, J. (2011). Neural Correlates of Antidepressant-Related Sexual Dysfunction: A Placebo-Controlled fMRI Study on Healthy Males Under Subchronic Paroxetine and Bupropion. Neuropsychopharmacology 36, 1837-1847.

Argyropoulos, S. V. \& Nutt, D. J. (2013). Anhedonia revisited: is there a role for dopaminetargeting drugs for depression? Journal of psychopharmacology 27, 869-77.

Beck, A. T., Ward, C. H., Mendelson, M., Mock, J. \& Erbaugh, J. (1961). An inventory for measuring depression. Archives General Psychiatry 4, 561-71.

Berridge, K. C. (2007). The debate over dopamine's role in reward: the case for incentive salience. Psychopharmacology 191, 391-431.

Berridge, K. C. \& Kringelbach, M. L. (2008). Affective neuroscience of pleasure: reward in humans and animals. Psychopharmacology 199, 457-480.

Berridge, K. C., Robinson, T. E. \& Aldridge, J. W. (2009). Dissecting components of reward:'liking', 'wanting', and learning. Current opinion in pharmacology 9, 65-73.

Bylsma, L. M., Morris, B. H. \& Rottenberg, J. (2008). A meta-analysis of emotional reactivity in major depressive disorder. Clinical psychology review 28, 676-691.

Carver, C. S. \& White, T. L. (1994). Behavioral inhibition, behavioral activation, and affective responses to impending reward and punishment: the BIS/BAS scales. Journal of personality and social psychology 67, 319 .

Collins, D. L., Neelin, P., Peters, T. M. \& Evans, A. C. (1994). Automatic 3D intersubject registration of MR volumetric data in standardized Talairach space. Journal of Computer Assisted Tomography 18, 192-205.

Corcoran, C., Wong, M. L. \& O'Keane, V. (2004). Bupropion in the management of apathy. J Psychopharmacol 18, 133-5.

Dayan, P. \& Balleine, B. W. (2002). Reward, motivation, and reinforcement learning. Neuron 36, 285-298.

de Araujo, I. E., Kringelbach, M. L., Rolls, E. T. \& Hobden, P. (2003). Representation of umami taste in the human brain. J Neurophysiol 90, 313-9.

Delgado, M. R., Jou, R. L., Ledoux, J. E. \& Phelps, E. A. (2009). Avoiding negative outcomes: tracking the mechanisms of avoidance learning in humans during fear conditioning. Front Behav Neurosci 3, 33.

Dunlop, B. W. \& Nemeroff, C. B. (2007). The role of dopamine in the pathophysiology of depression. Arch Gen Psychiatry 64, 327-37.

Dwoskin, L. P., Rauhut, A. S., King-Pospisil, K. A. \& Bardo, M. T. (2006). Review of the pharmacology and clinical profile of bupropion, an antidepressant and tobacco use cessation agent. CNS drug reviews 12, 178-207.

Epstein, J., Pan, H., Kocsis, J. H., Yang, Y., Butler, T., Chusid, J., Hochberg, H., Murrough, J., Strohmayer, E., Stern, E. \& Silbersweig, D. A. (2006). Lack of ventral striatal response to positive stimuli in depressed versus normal subjects. American Journal of Psychiatry 163, 1784-90. 
Fawcett, J., Clark, D. C., Scheftner, W. A. \& Gibbons, R. D. (1983). Assessing anhedonia in psychiatric patients. Arch Gen Psychiatry 40, 79-84.

Forbes, E. E., Hariri, A. R., Martin, S. L., Silk, J. S., Moyles, D. L., Fisher, P. M., Brown, S. M., Ryan, N. D., Birmaher, B., Axelson, D. A. \& Dahl, R. E. (2009). Altered striatal activation predicting real-world positive affect in adolescent major depressive disorder. Am J Psychiatry 166, 64-73.

Frey, A.-L., Malinowska, L., Harley, K., Salhi, L., Iqbal, S., Sharma, S. \& McCabe, C. (2015). Investigating subtypes of reward processing deficits as trait markers for depression. Translational Developmental Psychiatry 3.

Friston, K. J., Glaser, D. E., Henson, R. N., Kiebel, S., Phillips, C. \& Ashburner, J. (2002). Classical and Bayesian inference in neuroimaging: applications. Neuroimage 16, 484-512.

Friston, K. J., Worsley, K. J., Frackowiak, R. S. J., Mazziotta, J. C. \& Evans, A. C. (1994). Assessing the significance of focal activations using their spatial extent. Human Brain Mapping 1, 214-220.

Gard, D. E., Kring, A. M., Gard, M. G., Horan, W. P. \& Green, M. F. (2007). Anhedonia in schizophrenia: distinctions between anticipatory and consummatory pleasure. Schizophrenia research 93, 253-60.

Garner, D. M., Olmsted, M. P., Bohr, Y. \& Garfinkel, P. E. (1982). The eating attitudes test: psychometric features and clinical correlates. Psychol Med 12, 871-8.

Harmer, C. J., Goodwin, G. M. \& Cowen, P. J. (2009). Why do antidepressants take so long to work? A cognitive neuropsychological model of antidepressant drug action. Br J Psychiatry 195, 102-8.

Horder, J., Harmer, C. J., Cowen, P. J. \& McCabe, C. Reduced neural response to reward following 7 days treatment with the cannabinoid $\mathrm{CB}(1)$ antagonist rimonabant in healthy volunteers. Int J Neuropsychopharmacol 13, 1103-13.

Kerr, D. L., McLaren, D. G., Mathy, R. M. \& Nitschke, J. B. (2012). Controllability modulates the anticipatory response in the human ventromedial prefrontal cortex. Frontiers in psychology 3. Kim, H., Shimojo, S. \& O'Doherty, J. P. (2010). Overlapping responses for the expectation of juice and money rewards in human ventromedial prefrontal cortex. Cerebral cortex, bhq145.

Knutson, B., Bhanji, J. P., Cooney, R. E., Atlas, L. Y. \& Gotlib, I. H. (2008). Neural responses to monetary incentives in major depression. Biol Psychiatry 63, 686-92.

Knutson, B. \& Greer, S. M. (2008). Anticipatory affect: neural correlates and consequences for choice. Philos Trans $R$ Soc Lond B Biol Sci 363, 3771-86.

Kringelbach, M. L. (2010). The hedonic brain: a functional neuroanatomy of human pleasure. Pleasures of the brain, 202-221.

Kumar, P., Waiter, G., Ahearn, T., Milders, M., Reid, I. \& Steele, J. D. (2008). Abnormal temporal difference reward-learning signals in major depression. Brain 131, 2084-93.

Liljeholm, M. \& O'Doherty, J. P. (2012). Contributions of the striatum to learning, motivation, and performance: an associative account. Trends in cognitive sciences 16, 467-475.

Luking, K. R., Neiman, J. S., Luby, J. L. \& Barch, D. M. (2015). Reduced Hedonic Capacity/Approach Motivation Relates to Blunted Responsivity to Gain and Loss Feedback in Children. Journal of Clinical Child \& Adolescent Psychology, 1-13.

M Pereira, V., Arias-Carrión, O., Machado, S., E Nardi, A. \& C Silva, A. (2014). Bupropion in the Depression-Related Sexual Dysfunction: A Systematic Review. CNS \& Neurological

Disorders-Drug Targets (Formerly Current Drug Targets-CNS \& Neurological Disorders) 13, 1079-1088.

McCabe, C. (2014). Neural correlates of anhedonia as a trait marker for depression. In Anhedonia: A Comprehensive Handbook Volume II, pp. 159-174. Springer.

McCabe, C., Cowen, P. J. \& Harmer, C. J. (2009a). Neural representation of reward in recovered depressed patients. Psychopharmacology (Berl) 205, 667-77.

McCabe, C., Cowen, P. J. \& Harmer, C. J. (2009b). Neural representation of reward in recovered depressed patients. Psychopharmacology 205, 667-77. 
McCabe, C., Mishor, Z., Cowen, P. J. \& Harmer, C. J. (2010). Diminished neural processing of aversive and rewarding stimuli during selective serotonin reuptake inhibitor treatment. Biol Psychiatry 67, 439-45.

Nutt, D., Demyttenaere, K., Janka, Z., Aarre, T., Bourin, M., Canonico, P. L., Carrasco, J. L. \& Stahl, S. (2007). The other face of depression, reduced positive affect: the role of catecholamines in causation and cure. J Psychopharmacol 21, 461-71.

O'Doherty, J., Rolls, E. T., Francis, S., Bowtell, R. \& McGlone, F. (2001). Representation of pleasant and aversive taste in the human brain. J Neurophysiol 85, 1315-21.

Opbroek, A., Delgado, P. L., Laukes, C., McGahuey, C., Katsanis, J., Moreno, F. A. \& Manber, R. (2002). Emotional blunting associated with SSRI-induced sexual dysfunction. Do SSRIs inhibit emotional responses? Int J Neuropsychopharmacol 5, 147-51.

Peciña, S. (2008). Opioid reward 'liking'and 'wanting' in the nucleus accumbens. Physiology \& behavior 94, 675-680.

Peciña, S. \& Berridge, K. C. (2005). Hedonic hot spot in nucleus accumbens shell: where do $\mu-$ opioids cause increased hedonic impact of sweetness? The Journal of neuroscience 25, 11777 11786.

Peciña, S., Smith, K. S. \& Berridge, K. C. (2006). Hedonic hot spots in the brain. The Neuroscientist 12, 500-511.

Peters, J. \& Buchel, C. (2010). Neural representations of subjective reward value. Behav Brain Res 213, 135-41.

Pizzagalli, D. A., Holmes, A. J., Dillon, D. G., Goetz, E. L., Birk, J. L., Bogdan, R., Dougherty, D. D., Iosifescu, D. V., Rauch, S. L. \& Fava, M. (2009a). Reduced caudate and nucleus accumbens response to rewards in unmedicated individuals with major depressive disorder. Am $J$ Psychiatry 166, 702-10.

Pizzagalli, D. A., Holmes, A. J., Dillon, D. G., Goetz, E. L., Birk, J. L., Ryan Bogdan, A., Dougherty, D. D., Iosifescu, D. V., Rauch, S. L. \& Fava, M. (2009b). Reduced caudate and nucleus accumbens response to rewards in unmedicated individuals with major depressive disorder. The American journal of psychiatry 166, 702-710.

Price, J., Cole, V. \& Goodwin, G. M. (2009). Emotional side-effects of selective serotonin reuptake inhibitors: qualitative study. Br J Psychiatry 195, 211-7.

Price, J. \& Drevets, W. C. (2009). Neurocircuitry of mood disorders. Neuropsychopharmacology Review 35, 192-216.

Rolls, E. T. \& McCabe, C. (2007). Enhanced affective brain representations of chocolate in cravers vs. non-cravers. Eur J Neurosci 26, 1067-76.

Rottenberg, J. (2007). Major Depressive Disorder: Emerging Evidence for Emotion Context Insensitivity.

Rottenberg, J., Gross, J. J. \& Gotlib, I. H. (2005). Emotion context insensitivity in major depressive disorder. J Abnorm Psychol 114, 627-39.

Scholl, J., Kolling, N., Nelissen, N., Wittmann, M. K., Harmer, C. J. \& Rushworth, M. F. (2015). The Good, the Bad, and the Irrelevant: Neural Mechanisms of Learning Real and Hypothetical Rewards and Effort. The Journal of Neuroscience 35, 11233-11251.

Scott, T. R., Edwards, E. M., Smith, C. A., Hilgert, K. G., Schwartz, G. J. \& Pritchard, T. C. (2005). Medial orbitofrontal cortex: its role in mediating satiety in the macaque. Chemical senses 30, i190.

Sescousse, G., Caldú, X., Segura, B. \& Dreher, J.-C. (2013). Processing of primary and secondary rewards: a quantitative meta-analysis and review of human functional neuroimaging studies. Neuroscience \& Biobehavioral Reviews 37, 681-696.

Sheline, Y. I., Barch, D. M., Donnelly, J. M., Ollinger, J. M., Snyder, A. Z. \& Mintun, M. A. (2001). Increased amygdala response to masked emotional faces in depressed subjects resolves with antidepressant treatment: an fMRI study. Biol Psychiatry 50, 651-8.

Shelton, R. C. \& Tomarken, A. J. (2001). Can recovery from depression be achieved? Psychiatr Serv 52, 1469-78. 
Sherdell, L., Waugh, C. E. \& Gotlib, I. H. (2012). Anticipatory pleasure predicts motivation for reward in major depression. J Abnorm Psychol 121, 51-60.

Smith, K. S. \& Berridge, K. C. (2005). The ventral pallidum and hedonic reward: neurochemical maps of sucrose "liking" and food intake. The Journal of neuroscience 25, 8637-8649.

Smoski, M. J., Felder, J., Bizzell, J., Green, S. R., Ernst, M., Lynch, T. R. \& Dichter, G. S. (2009). fMRI of alterations in reward selection, anticipation, and feedback in major depressive disorder. J Affect Disord 118, 69-78.

Snaith, R. P., Hamilton, M., Morley, S., Humayan, A., Hargreaves, D. \& Trigwell, P. (1995). A scale for the assessment of hedonic tone the Snaith-Hamilton Pleasure Scale. Br J Psychiatry 167, 99-103.

Spijker, J., Bijl, R. V., de Graaf, R. \& Nolen, W. A. (2001). Determinants of poor 1-year outcome of DSM-III-R major depression in the general population: results of the Netherlands Mental Health Survey and Incidence Study (NEMESIS). Acta Psychiatr Scand 103, 122-30. Spitzer, R. L., Williams, J. B., Gibbon, M. \& First, M. B. (2004). Structured Clinical Interview for the DSM-IV (SCID-I/P).

Stahl, S. M., Pradko, J. F., Haight, B. R., Modell, J. G., Rockett, C. B. \& Learned-Coughlin, S. (2004). A review of the neuropharmacology of bupropion, a dual norepinephrine and dopamine reuptake inhibitor. Primary care companion to the Journal of clinical psychiatry 6, 159.

Surguladze, S. A., Young, A. W., Senior, C., Brebion, G., Travis, M. J. \& Phillips, M. L. (2004). Recognition accuracy and response bias to happy and sad facial expressions in patients with major depression. Neuropsychology 18, 212-8.

Treadway, M. T., Bossaller, N. A., Shelton, R. C. \& Zald, D. H. (2012). Effort-based decisionmaking in major depressive disorder: a translational model of motivational anhedonia. $J$ Abnorm Psychol 121, 553-8.

Treadway, M. T. \& Zald, D. H. (2011). Reconsidering anhedonia in depression: lessons from translational neuroscience. Neurosci Biobehav Rev 35, 537-55.

Tudge, L., Williams, C., Cowen, P. J. \& McCabe, C. (2015). Neural effects of cannabinoid CB1 neutral antagonist tetrahydrocannabivarin on food reward and aversion in healthy volunteers. Int $J$ Neuropsychopharmacol 18.

Ubl, B., Kuehner, C., Kirsch, P., Ruttorf, M., Diener, C. \& Flor, H. (2015). Altered neural reward and loss processing and prediction error signalling in depression. Soc Cogn Affect Neurosci 10, 1102-12.

von Zerssen, D., Strian, F. \& Schwarz, D. (1974). Evaluation of depressive states, especially in longitudinal studies. Modern Problems of Pharmacopsychiatry 7, 189-202.

Wheeler, R. A. \& Carelli, R. M. (2006). The neuroscience of pleasure. Focus on "Ventral pallidum firing codes hedonic reward: when a bad taste turns good". J Neurophysiol 96, 2175-6.

Wiers, C. E., Stelzel, C., Park, S. Q., Gawron, C. K., Ludwig, V. U., Gutwinski, S., Heinz, A., Lindenmeyer, J., Wiers, R. W. \& Walter, H. (2014). Neural correlates of alcohol-approach bias in alcohol addiction: the spirit is willing but the flesh is weak for spirits. Neuropsychopharmacology 39, 688-697.

Wilson, J. L., Jenkinson, M., de Araujo, I., Kringelbach, M. L., Rolls, E. T. \& Jezzard, P. (2002). Fast, fully automated global and local magnetic field optimization for fMRI of the human brain. Neuroimage 17, 967-76.

Worsley, K. J., Marrett, P., Neelin, A. C., Friston, K. J. \& Evans, A. C. (1996). A unified statistical approach for determining significant signals in images of cerebral activation. . Human Brain Mapping 4, 58:73.

Yang, X. H., Huang, J., Zhu, C. Y., Wang, Y. F., Cheung, E. F., Chan, R. C. \& Xie, G. R. (2014). Motivational deficits in effort-based decision making in individuals with subsyndromal depression, first-episode and remitted depression patients. Psychiatry Res 220, 874-82.

Zhang, W.-N., Chang, S.-H., Guo, L.-Y., Zhang, K.-L. \& Wang, J. (2013). The neural correlates of reward-related processing in major depressive disorder: a meta-analysis of functional magnetic resonance imaging studies. Journal of affective disorders 151, 531-539. 
Zisook, S., Rush, A. J., Haight, B. R., Clines, D. C. \& Rockett, C. B. (2006). Use of bupropion in combination with serotonin reuptake inhibitors. Biological psychiatry 59, 203-210. 
Dr Ciara McCabe.

School of Psychology and Clinical Language Sciences, University of Reading, Reading RG6 6AL. 